\title{
Electrical Properties of Teflon and Ceramic Capacitors at High Temperatures
}

\author{
A.N. Hammoud \\ Sverdrup Technology, Inc. \\ Lewis Research Center Group \\ Brook Park, Ohio
}

and

E.D. Baumann, I.T. Myers, and E. Overton

Lewis Research Center

Cleveland, Ohio

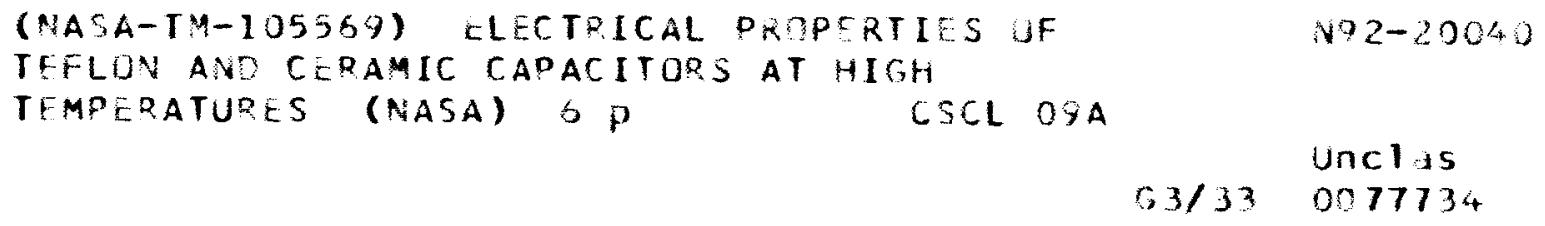

Prepared for the

1992 International Symposium on Electrical Insulation

sponsored by the Institute of Electrical and Electronics Engineers

Dielectrics and Electrical Insulation Society

Baltimore, Maryland, June 7-9, 1992 


\section{ELECTRICAL PROPERTIES OF TEFLON AND CERAMIC CAPACITORS AT HIGH TEMPERATURES}

\author{
A.N. Hammoud \\ Sverdrup Technology, Inc. \\ Lewis Research Center Group \\ Brook Park, Ohio 44142
}

\author{
E.D. Baumann, I.T. Myers, \\ and $E$. Overton \\ National Aeronautics and Space Administration \\ Lewis Research Center \\ Cleveland, Ohio 44135
}

\begin{abstract}
Space power systems and components are often required to operate efficiently and reliably in harsh environments where stresses, such as high temperature, are encountered. These systems must, therefore, withstand exposure to high temperature while still providing good electrical and other functional properties. In this work, experiments were carried out to evaluate teflon and ceramic capacitors for potential use in high temperature applications. The capacitors were characterized in terms of their capacitance and dielectric loss as a function of temperature, up to $200^{\circ} \mathrm{C}$. At a given temperature, these properties were obtained in a frequency range of $50 \mathrm{~Hz}$ to $100 \mathrm{kHz}$. DC leakage current measurements were also performed in a temperature range from 25 to $200{ }^{\circ} \mathrm{C}$. The results obtained are discussed and conclusions are made concerning the suitability of the capacitors investigated for high temperature applications.
\end{abstract}

\section{INTRODUCTION}

Electrical components and systems are often required to operate reliably in harsh environments where stresses of different kinds and intensities are encountered. High temperature constitutes one of these stresses which exists in space-based as well as terrestrial environments. Space exploration missions (lunar base), nuclear-powered space vehicles, integrated engine electronics, satellite power conditioning, and SDI systems are examples of advanced space electric power systems which will require electrical components capable of long-term operation at high temperatures. Terrestrial applications where high temperature is present include well logging, geothermal energy extraction, nuclear power plants, and automotive and locomotive engine electronics.

High temperatures can also be developed internally due to the fact that most power processing and conditioning devices generate heat during their normal mode of operation. The generation of heat and its build-up are believed to greatly influence the performance of these devices as they cause gradual degradation which eventually leads to catastrophic failure. This internally developed thermal stress is becoming more severe as the currently emerging demand for aerospace technology places a great emphasis on increasing the energy densities and raising the power levels of space-based power systems and components. For instance, future plans for many space exploration missions call for tremendous increases in the power capability to a magnitude on the order of megawatts [1]. These requirements will certainly result in raising the operating temperature of the devices concerned [2].

The development of high temperature power components and devices is therefore necessary to meet the challenges of advanced space power technology with objectives to reduce size and weight, increase packaging density, improve performance, and increase lifetime. Among the various benefits that can be gained from the availability of high temperature electronics include reduced launch cost, simplified thermal management systems, and improved device survivability. For example, it has been reported that high temperature components can make significant improvement in reliability for satellite missions on the order of a hundred years [3].

Teflon and ceramic power capacitors were evaluated for potential use in high temperature applications. The capacitors were characterized in terms of their capacitance and dielectric loss as a function of temperature, up to $200{ }^{\circ} \mathrm{C}$, in a frequency range of $50 \mathrm{~Hz}$ to $100 \mathrm{kHz}$. The effect of temperature on the DC leakage current was also determined. In this paper, the experimental procedures and the results obtained are discussed.

\section{EXPERIMENTAL PROCEDURES}

In an earlier work, the authors investigated off-the-shelf high temperature capacitors that employed glass, tefion, or solid tantalum as the dielectric [4]. These capacitors were signal-level devices, and some required derating with temperature. It was found that amongst the three capacitors tested, the teflon capacitor had shown superiority in terms of thermal stability. An effort was then made to develop and characterize power-level capacitors suitable for operation in high temperature environments. In this work, power capacitors made of metallized-teflon (Component Research Co.l and COG/NPO ceramic (Olean Advanced Products) were evaluated at high temperatures. Table I lists some of the design requirements and the manufacturer's specifications $[5,6]$.

Capacitance and dissipation factor of the capacitors were obtained as a function of temperature, up to $200^{\circ} \mathrm{C}$, using a Hotpack benchtop oven. At a given temperature, these properties were obtained in a frequency range of $50 \mathrm{~Hz}$ to 100 kHz using a GenRad Model 1689 Digibridge. DC 
leakage current measurements were also performed in a temperature range from 25 to $200{ }^{\circ} \mathrm{C}$ using a Keithley Model 237 Source-Measure Unit. In performing the leakage current measurements, the capacitor under test was allowed to charge by supplying the proper voltage through a $10 \mathrm{k} \Omega$ current-limiting resistor. DC voltages of $200 \mathrm{~V}$ and $500 \mathrm{~V}$ were applied for the teflon and the ceramic capacitor, respectively. The leakage current was recorded 5 minutes after voltage application. Such a time was required for the current to reach stability. Each capacitor was then discharged completely before the next measurement was made.

\section{RESULTS AND DISCUSSIONS}

The change in capacitance of the teflon capacitor with temperature is shown in Figure 1. It can be clearly seen that the capacitor undergoes gradual but slight reduction in its capacitance with increasing temperature. This decrease, which becomes noticeable when the temperature exceeds $125^{\circ} \mathrm{C}$, is very minimal as it amounts, even at the highest temperature of $200{ }^{\circ} \mathrm{C}$, to only about $2 \%$ of its original value. In addition to being relatively stable with temperature, the teflon capacitor displayed no capacitance change with frequency. it should be noted that the results shown in Figure 1 not only represent those taken at the lowest 150 $\mathrm{Hz})$ and the highest $(100 \mathrm{kHz})$ frequency, but rather the data for the full frequency range between $50 \mathrm{~Hz}$ and 100 kHz.

Similarly, the frequency was found to have little effect on the change of capacitance of the ceramic capacitor as depicted in Figure 2. In terms of temperature, the ceramic capacitor displayed excellent thermal stability as its capacitance remained relatively constant from 25 to $200^{\circ} \mathrm{C}$. This is expected as ceramics, especially the COG type, are known to exhibit good stability with temperature.

The dissipation factor of the teflon capacitor as a function of temperature and at different frequencies is shown in Figure 3. It is evident that the dissipation factor, at a given frequency, exhibits a slight increase with increasing temperature. The increase in the loss, which occurs mainly in the high temperature regime, can be attributed to increasing the ionic conduction caused by some ionic mechanism which is thermally activated [7]. At a given temperature, the dissipation factor seems to increase dramatically with an increase in frequency. Although most polymeric dielectrics are known to undergo an increase in their loss factor with frequency due to dipole orientation, space charge accumula- tion, electronic polarization, and molecular relaxation, the increase is typically modest in nature and occurs at very high frequencies. Therefore, the dramatic increase in the dissipation factor with frequency as presented in Figure 3 cannot be attributed to the polymer film but rather to the resistance of the terminations and leads of the capacitors. Proper design techniques and improved manufacturing processes will certainly minimize, if not eliminate, these losses.

The ceramic capacitor shows similar trend in its dissipation factor with temperature as that of the teflon capacitor only at high frequencies, as shown in Figure 4. That is, a steady but very slight increase in the dissipation factor is associated with increase in temperature at frequencies at and above $20 \mathrm{kHz}$. At the low frequencies, namely $50 \mathrm{~Hz}$ and $1 \mathrm{kHz}$, this property, however, exhibits significant increase with temperature. This effect is more profound at $50 \mathrm{~Hz}$ and when the temperature exceeds $100^{\circ} \mathrm{C}$. The change in the dielectric loss behavior of the ceramic capacitor with frequency and temperature can be attributed to many factors and mechanisms such as the presence of ionic impurities, grain boundary effects, interfacial polarization, and charge transport phenomena.

Figure 5 depicts the DC leakage current of the capacitors as a function of temperature. It can be seen that the leakage currents for both capacitors increase with temperature but with different intensities. That is, while the teflon capacitor starts to exhibit a moderate increase in leakage current at temperatures beyond $150^{\circ} \mathrm{C}$, its ceramic counterpart undergoes a marked increase as the temperature exceeds $100^{\circ} \mathrm{C}$. For example, the increase in the leakage current of the ceramic capacitor amounted to about three orders of magnitude when temperature of $200{ }^{\circ} \mathrm{C}$ is reached. As pointed out earlier, interfacial polarization losses as well as conduction losses by charge carriers in the ceramic dielectric might have been responsible for the increase in the leakage current with temperature. The application of higher bias voltage may have been also a factor as $200 \mathrm{~V}$ and $\mathbf{5 0 0}$ $\checkmark$ were applied in these tests to the teflon and ceramic capacitors, respectively.

\section{CONCLUSION}

The results of this work indicate that both the teflon and ceramic capacitors display temperature-dependence in their dielectric properties. The frequency was also found to have an effect on these properties; in particular, the dissipation factor. Further experimental studies, such as thermal aging

TABLE 1. CAPACITORS SPECIFICATIONS [5,6]

\begin{tabular}{|c|c|c|}
\hline Property & Teflon & Ceramic \\
\hline Capacitance $(\mu \mathrm{F})$ & 1.0 & 1.0 \\
\hline Capacitance Tolerance (\%) & 5 & \pm 10 \\
\hline Voltage (VDC) & 200 & 500 \\
\hline Operating Temperature $\left({ }^{\circ} \mathrm{C}\right)$ & -65 to +200 & -55 to +200 \\
\hline Dissipation Factor $(\%)$ & 0.05 Max @ $25^{\circ} \mathrm{C}$ & 0.15 Max @ $25^{\circ} \mathrm{C}$ \\
\hline
\end{tabular}


and testing at full rated power, are required to better and fully characterize these and other capacitors for potential use in high temperature environments.

\section{ACKNOWLEDGMENTS}

This work was supported by NASA Lewis Research Center, Contract \#NAS3-25266, Task Order \#5423-01, "High Temperature Dielectrics."

\section{REFERENCES}

[1] R. W. Bercaw, "Toward an Electrical Power Utility for Space Exploration," Proceedings of the European Space Power Conference, Madrid, Spain, October 2-6, 1989.

[2] E. Sugimoto, "Applications of Polyimide Films to the Electrical and Electronic Industries in Japan," IEEE Electrical Insulation Magazine, Vol. 5, No. 1, 1989.

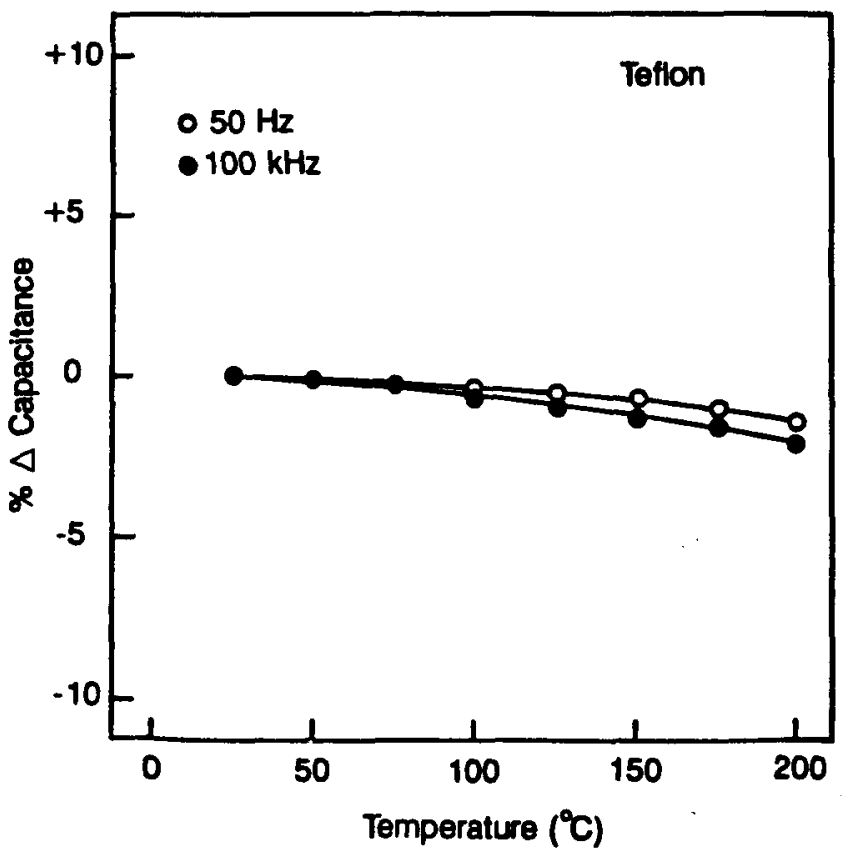

Figure 1. Change in capacitance of teflon capacitor with temperature.
[3] J. Burnham, "Leakage Current-Voltage Characteristics of Solid Tantalum Capacitors at Very High Temperatures," Proceedings of the 24th Electronic Components Conference, Washington, D.C., May 13-15, 1974.

[4] A. N. Hammoud, E. D. Baumann, I. T. Myers, and E. Overton, "Electrical Characterization of Glass, Tefion, and Tantalum Capacitors at High Temperatures," 1991 Annuai Report, Conference on Electrical Insulation and Dielectric Phenomena, Knoxville, Tennessee, October 20-23, 1991.

[5] Component Research Company, High Reliability Film Capacitors, Catalog W.

[6] Olean Advanced Products, Chip Capacitor No. AOL0959-01.

[7] R. Bartnikas, "Dielectric Loss in Solids, " Engineering Dielectrics, Vol. IIA, ASTM Publication 783, 1983.

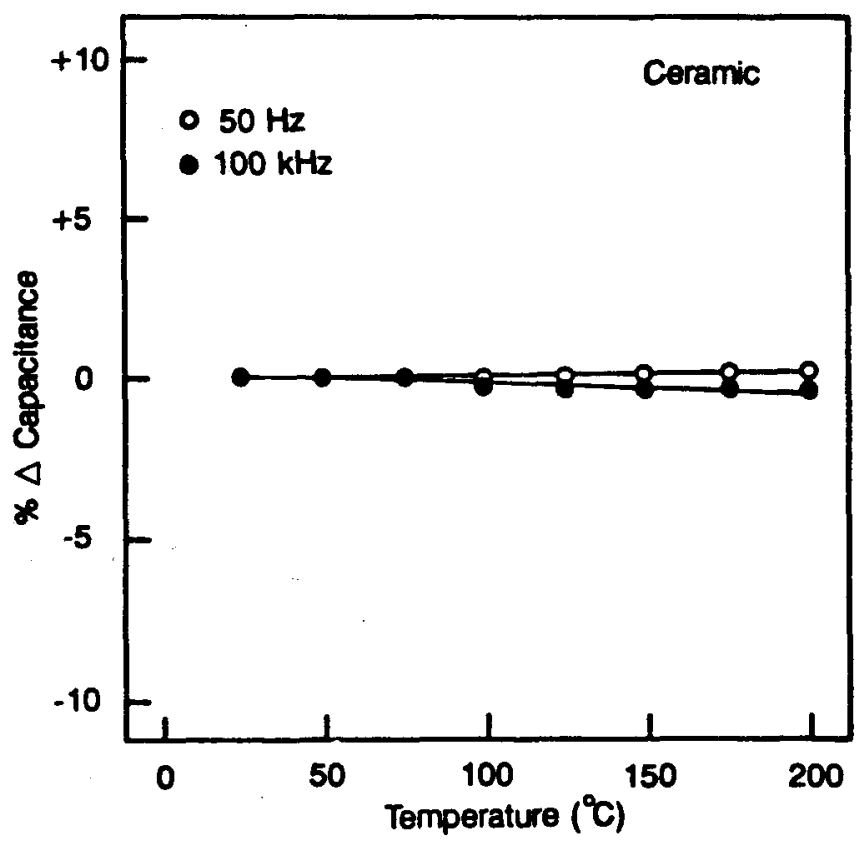

Figure 2. Change in capacitance of ceramic capacitor with temperature. 


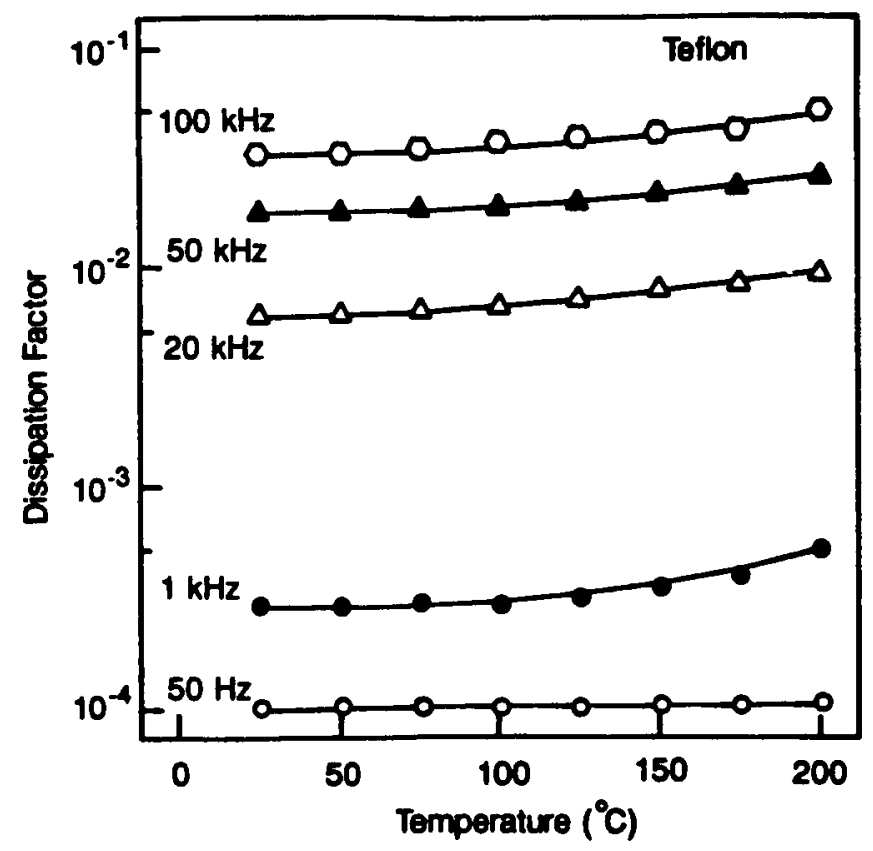

Figure 3. Dissipation factor of teflon capacitor as a function of temperature.

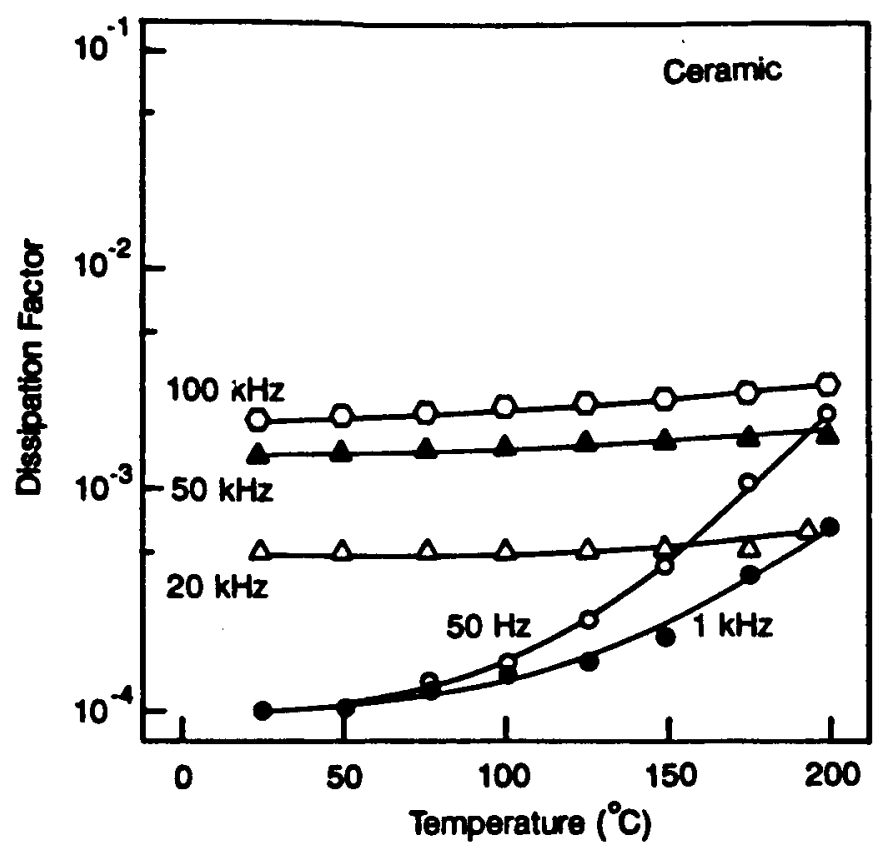

Figure 4. Dissipation factor of ceramic capacitor as a function of temperature.

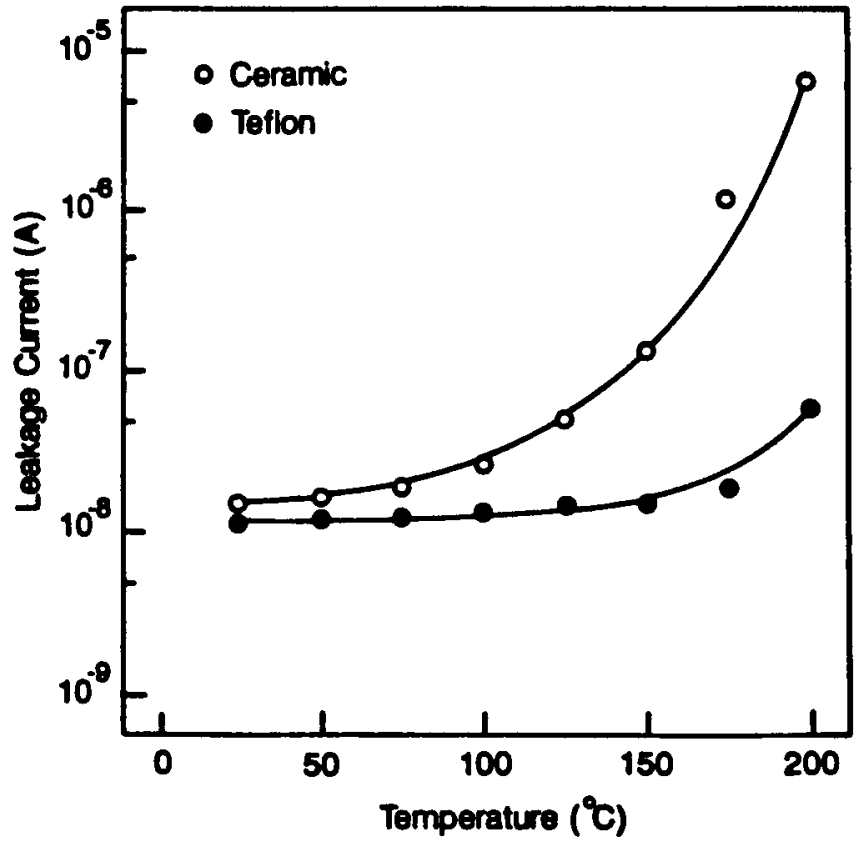

Figure 5. Comparison of leakage currents with temperature. 


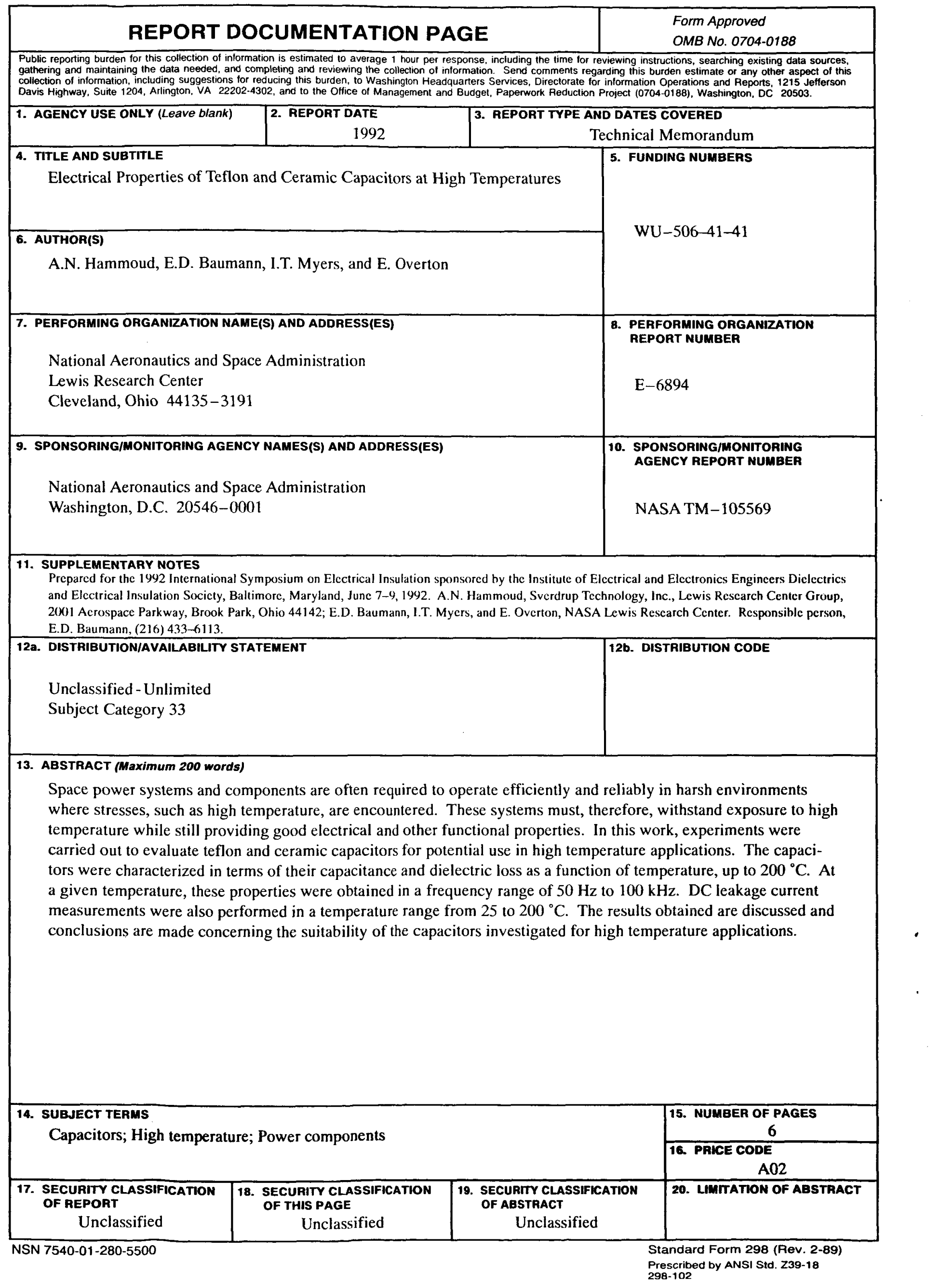

